Magnetic toy ingestion leading to jejunocecal fistula in a child. Saudi Med J. 2010;31:442-4.

11. Saeed A, Johal NS, Aslam A, Brain J, Fitzgerald RJ. Attraction Problems Following Magnet Ingestion. Ann R Coll Surg Engl. 2009;91:W10-2.

12. Dutta S, Barzin A. MUltiple magnet ingestion as a source of severe gastrointestinal complications requiring surgical intervention. Arch Pediatr Adolesc Med. 2008;162:123-5.

13. Treasury. Competition and Consumer Act 2010 - Consumer Protection Notice No. 5 of 2012 - Imposition of Permanent Ban on Small, High Powered Magnets [Internet]. [cited 2013 Dec 29]. Available from: http://www.comlaw.gov.au/Details/ F2012L02171

\section{Giant choledochal cyst}

\section{Introduction}

The incidence of choledochal cyst is 1 in 100,000 to 150,000 live births with a 3:1 to 4:1 female preponderance. It is reportedly more common in Asian populations(particularly Japanese). ${ }^{1}$ More than $60 \%$ present during the first year of life andabout $20 \%$ presents in adulthood. ${ }^{2}$ The etiology of choledochal cyst is still controversial. The "common channel theory" proposed by Babbitt et alis the most commonly accepted theory. ${ }^{3} \mathrm{We}$ report the case of a choledochal cyst type 1 in a 14-year-old girl in which there was huge dilatation of the common bile duct occupying almost right half of the abdomen and containing about 2400 cc of bile.

\section{Case Report}

A 14-year-old girl was admitted with a 3-day history of pain abdomen, jaundice and fever. She noticed fullness in the right side of herabdomen since 1 year which was asymptomatic but progressive in nature. She also had past history of fever and jaundice one and half month agofor which she was hospitalized.On general examination, she had tachycardia with mild pyrexia.Per abdomen examination revealed tenderness in the right hypochondrium and a well defined cystic lump in the whole right hemiabdomen extending from right hypochondrium to right iliac fossa. Blood investigations revealed hemoglobin $8.9 \mathrm{~g} / \mathrm{dL}$ and total leukocyte count of $14600 /$ cumm with $76 \%$ polymorphs and $20 \%$ lymphocytes. Serum bilirubin was 4.2 mgwith a direct component of $2.5 \mathrm{mg} / \mathrm{dL}$. Alkaline phosphates was elevated (789U/L) and ALT was 153U/L. Serum amylase was normal. Ultrasonography revealed cystic lesion arising from porta suggesting choledochal cyst type1.Magnetic resonant cholangiopancreatogram confirmed this diagnosis (Figure 1-A \& 1-B). She was managed with IV antibiotics, adequate hydration and symptomatic care. She responded well and became painfree andafebrile. Surgery was planned. On exploration, there was a giant choledochal cyst of approximately $15 \mathrm{~cm} \times 18 \mathrm{~cm} \times 9 \mathrm{~cm}$ sizes, occupying almost the entire right half of the abdomen (Figure 2). The duodenum and right colon were pushed to left. Aspiration yielded 2400cc of bile. The entire cyst was dissected out from the hilum superiorly tothe junction with pancreatic ductinferiorly. Portal vein and hepatic artery were safeguarded. There were dense pericholecystic adhesions due to previous attacks of cholangitis. The cyst along with the gall bladder was excised. Roux en Y hepaticojejunostomy was performed to reestablish the biliary enteric communication. Oral feeding was initiatedsecond day postoperative. ALP touched baseline after the seventh

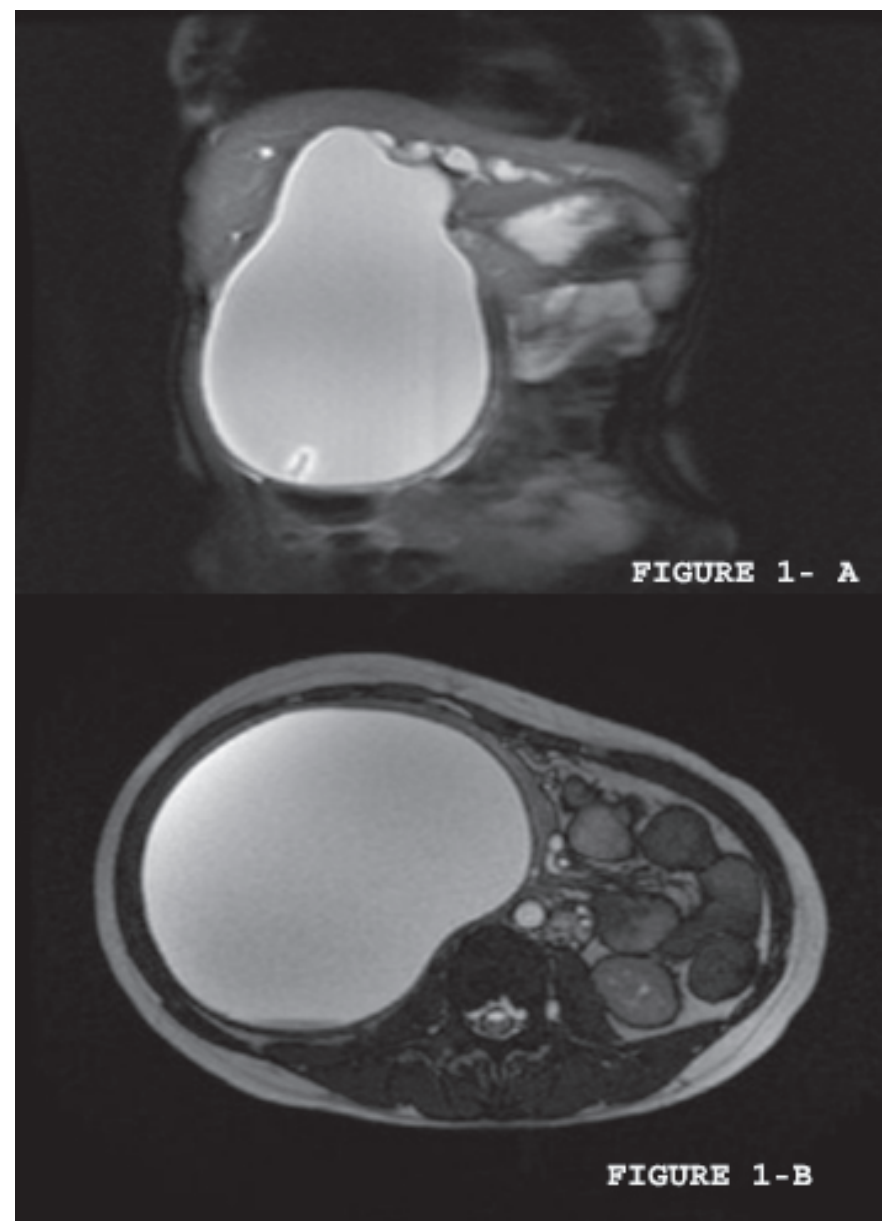

Figure 1: (A\&B) MRCP showing coronal and cross sectional view of giant choledochal cyst respectively 


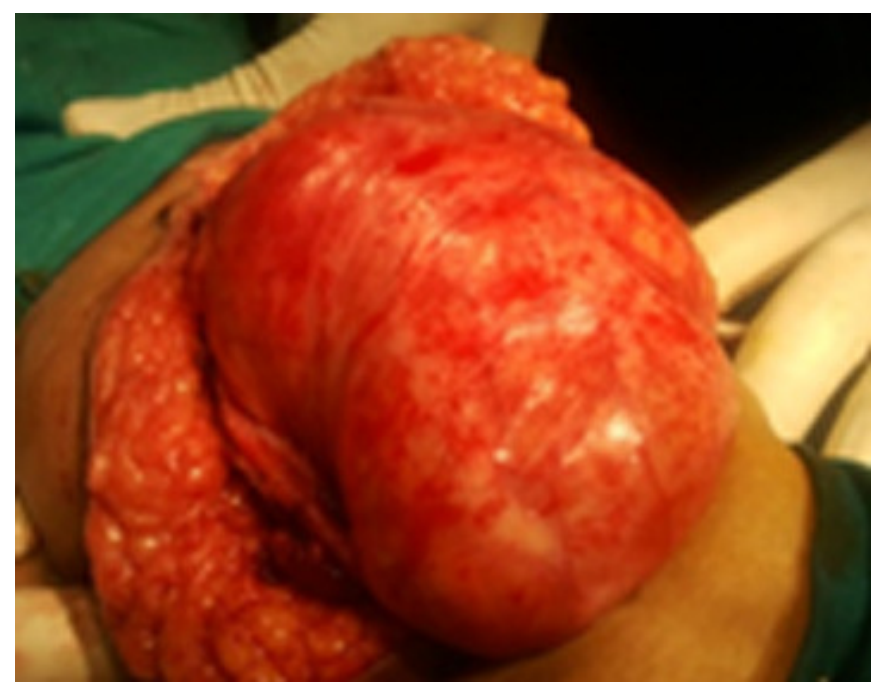

Figure 2: Intra operative photograph of giant choledochal cyst.

postoperative day.There was no evidence of malignancy on histopathological examination. The patient is presently doingwell at 1-year follow up.

\section{Discussion}

Choledochal cysts are rare congenital cystic dilatations of the biliary tract that can involve the intra- or extrahepatic bile ducts. The size of choledochal cyst varies, and the maximum diameter of cyst can reach upto $20 \mathrm{~cm} .{ }^{4}$

The classical triad of abdominal pain, jaundice and a right hypochondrial mass (as was in our case) is seen in less than $20 \%$ of patients. The main diagnostic tool for detection of a choledochal cyst, especially in childhood, is ultrasonography. Magnetic resonance cholangiopancreatography (MRCP) is the best method for noninvasive imaging of bile duct cysts. Surgery is the treatment of choice for a choledochal cyst. Complete excision of all cystic tissue is recommended because of the risk of recurrent cholangitis and the high risk of malignant degeneration. The risk of malignancy ranges from $3.2 \%$ to $39.4 \%$. The risk of cancer in patients who had choledochal cyst diagnosed in the first decade is $0.7 \%, 11$ to 20 years is $6.8 \%$ and more than 20years is $14.3 \% .{ }^{5}$ Robot-assisted resection of choledochal cysts and hepaticojejunostomyis therecently introduced modality in cyst management.

MANISH KUMAR KHARE MANISH DEWANGAN TARUN NAIK MANOJ KUMAR MOHANTY
Department of General Surgery JLN Hospital \& Research Centre, Bhilai

Chhattisgarh

Email: mkkhare69@gmail.com

\section{References}

1. Chung D.H. Pediatric Surgery. Townsend, Beauchamp, Evers, Mattox. Sabiston Textbook of Surgery $19^{\text {th }}$ edition: Page-1853

2. Söreide K, Körner H, Havnen J, Söreide JA. Bile duct cysts in adults. Br J Surg. 2004;91:1538-48.

3. Babbitt DP. Congenital choledochal cysts: new etiological concept based on anomalous relationships of the common bile duct and pancreatic bulb. Ann Radiol (Paris). 1969;12:231-40.

4. Choi JI, Lall C, Bhargava P, Imagawa DK. Giant choledochal cyst mimicking massive gall bladder hydrops in an adult patient: multi detector computed tomography and magnetic resonance imaging findings correlated to gross and histopathological findings. J CIin Imaging Sci. 2013;3:45

5. Voyles CR, Smadja C, Shands WC, Blumgart LA.Carcinoma in Choledochal cysts-age related incidence. Arch Surg. 1983;118:986-8.

\section{Duodenal Leishmaniasis Mimicking Celiac Disease}

\section{Introduction}

Visceral leismaniasis is considered as opportunistic infection in immunosuppressed patients particularly HIV infected. However, in the endemic areas like India, South America, Northeast Africa, and the Mediterranean basin it is quite common in immunocompetent persons as well. The atypical presentation of leishmaniasis is usually in association with HIV coinfection. ${ }^{1-3}$ We present a case of atypical presentation of leishmania infection in a non immunocompromised patient who came with clinical symptoms mimicking celiac disease.

\section{Case report}

A 32 year old female presented in gastroenterology OPD with complaints of chronic diarrhea and weight loss for one year and fever for one month. Blood tests revealed normocytic normochromic anemia and leucocytosis. Anti transglutaminase 